\title{
Slow and Steady: \\ Readiness, Pretreatment Weekly Strengthening Activity, and Pediatric Weight Management Program Completion
}

\author{
Daniel E. Ehrmann, BS, Bethany J. Sallinen, PhD,2,3 Heidi B. IglayReger, PhD, \\ Paul M. Gordon, PhD, MPH, and Susan J. Woolford, MD, $\mathrm{MPH}^{2,5}$
}

\section{Abstract}

Background: Pediatric weight management programs have substantial attrition rates, which have led to recommendations to assess readiness prior to enrollment. Both pretreatment readiness scales and behaviors, such as exercise, have been theorized to predict subsequent program completion. The purpose of this study was to explore the role of self-reported pretreatment exercise in adolescents on completion of a pediatric weight management program and to explore the predictive ability of standard readiness scales.

Methods: A total of 146 obese (BMI $\geq 95^{\text {th }}$ percentile) pediatric (ages 11-18) participants joined a 6-month multidisciplinary weight management program between March, 2007, and July, 2010. Completers were compared retrospectively to noncompleters on demographic, readiness, and pretreatment exercise practices from clinic-developed intake questionnaires using univariate analyses. Regression analyses specified the degree to which these variables predicted program completion.

Results: The 6-month completion rate was 53\%. There was no relationship between self-reported readiness and program completion. Self-reported pretreatment weekly strengthening activity (SA) was significantly associated with program completion, compared to those who performed SA either never [univariate odds ratio (OR) 3.18, 95\% confidence interval (CI) $1.51-6.68$, $p=0.002$; multivariate OR $2.43,95 \%$ CI $1.06-5.58, p=0.036$ ] or daily (univariate OR $4.90,95 \%$ CI $1.74-13.77, p=0.002$; multivariate OR 4.69, 95\% CI 1.45-15.14, $p=0.010$ ). No relationship was found between other forms of exercise and program completion.

Conclusions: Self-reported pretreatment weekly SA, but not standard readiness scales, predicted pediatric weight management program completion.

\section{Introduction}

$\Delta$ pproximately 1 child out of every 6 children in America is obese. ${ }^{1,2}$ Although recent data suggest a slowing of the childhood obesity epidemic compared to the upsurge of the 1980s and 1990s, it remains an important public health concern. ${ }^{2,3}$ Childhood obesity accounts for increased pediatric healthcare use and expenditures and will likely increase future morbidity and premature mortality from preventable cardiovascular and metabolic complications. ${ }^{4-6}$ This is expected to result in exceptionally high future healthcare costs and diminished health-related quality of life..$^{5-7}$ Not surprisingly, comprehensive pediatric weight management programs have attempted to slow or reverse pediatric weight gain to reduce current and subsequent complications.

However, the overall effectiveness of pediatric weight management programs is modest, in part due to the substantial rates of program attrition. ${ }^{8,9}$ The literature examining predictors of completion and attrition in pediatric comprehensive weight management ${ }^{10}$ has thus far revealed demographic (single-parent household, black, Medicaid recipients, low family income), ${ }^{11-14}$ psychological (adolescent depression, lower self-concept) ${ }^{14}$ medical (higher BMI, obesity-related medical conditions), ${ }^{12,14,15}$ logistical

\footnotetext{
'University of Michigan Medical School, Ann Arbor, MI.

${ }^{2}$ Department of Pediatrics and Communicable Diseases, University of Michigan, Ann Arbor, MI.

${ }^{3}$ Division of Child Behavioral Health, University of Michigan, Ann Arbor, MI.

${ }^{4}$ Department of Physical Medicine and Rehabilitation, University of Michigan, Ann Arbor, MI.

${ }^{5}$ Child Health Evaluation and Research (CHEAR) Unit, Division of General Pediatrics, University of Michigan, Ann Arbor, MI.
} 
(scheduling, parking, location), ${ }^{16}$ and program-specific (satisfaction) predictors of program attrition. ${ }^{11,16}$

The high attrition rates combined with these complex, multifactorial predictors have led to recommendations for gauging adolescent "readiness" prior to joining a weight management program. ${ }^{17-20}$ To date, one of the most popular ways to gauge readiness involves the use of readiness rulers aimed at assessing interest in achieving behavior change and confidence in oneself to achieve health-related goals. ${ }^{21,22}$ However, although these scales have been useful in assessing adolescents' readiness to change some behaviors (e.g., diet), ${ }^{23,24}$ their ability to predict pediatric weight management program completion and ultimately weight loss remains unclear. ${ }^{25}$

Therefore, some have proposed analyzing pretreatment health behaviors (e.g., diet, exercise), in addition to measuring stated readiness, to better understand the characteristics of program completers and noncompleters. ${ }^{26-28}$ Pretreatment behaviors may reflect robust characteristics related to readiness to change, ${ }^{26,28}$ and have performed better than some self-reported scales of pretreatment motivation/readiness in predicting weight management program completion in adults. ${ }^{29}$ Furthermore, a history of maladaptive behavior prior to initiation of a weight loss program may identify those likely to "burn out" after initial motivation wanes. ${ }^{30}$ With regard to pretreatment selfreported exercise, only two adult studies have been conducted to date, with mixed results. ${ }^{31,32}$ To our knowledge, no studies exist that explore the impact of pretreatment exercise on pediatric weight management program completion.

This retrospective analysis was designed to further explore the role of self-reported pretreatment exercise status on program completion while also exploring the predictive ability of standard measures of readiness. We hypothesized that higher levels of pretreatment exercise would be associated with higher levels of program completion and that standard measures of readiness would fail to have any association with the outcome.

\section{Methods}

\section{Study Design, Sample, and Program Overview}

We performed a retrospective analysis of new patient intake questionnaires and program completion data from 146 obese adolescents (aged 11-18) who entered the Michigan Pediatric Outpatient Weight Evaluation and Reduction (MPOWER) program between March, 2007, and July, 2010. To be eligible for the MPOWER program, patients were required to have a BMI at or above the $95^{\text {th }}$ percentile for age and sex and be between 11 and 18 years of age at the time of enrollment. The MPOWER program is a 6-month, intensive, multidisciplinary weight management program developed at the University of Michigan that includes weekly aerobic and strengthening activities (SAs), biweekly nutrition group classes, and monthly individual and group behavioral sessions aimed at addressing issues such as motivation and goal setting. The family- focused intervention is based on the self-determination theory and incorporates motivational interviewing and evidence-based behavior change strategies. ${ }^{17,33-35}$ All patients receive a comprehensive multidisciplinary initial evaluation, during which they meet with a pediatrician, registered dietitian, pediatric psychologist, social worker, and exercise physiologist. Baseline data across multiple domains (parent and adolescent enrollment questionnaires, laboratory and anthropomorphic measurements, psychological measures, nutritional logs, etc.) are collected prior to joining the program. After the initial consultation, prospective patients return in 1 week to discuss the results of the intake assessment and engage in collaborative treatment planning with team members. During this visit, families receive detailed information about the program and determine whether they wish to join. Payment for the program is made on a sliding scale relative to the participants' family income and is free for many participants.

\section{Survey Instrument and Data Collection}

Adolescents completed an enrollment questionnaire prior to being seen at the MPOWER program. The questionnaire focused on the adolescents' demographics, medical history, weight history, social support, eating habits, lifestyle, physical activity, and goals. With regard to physical activity, two items ascertained pretreatment exercise participation. First, we used an item from the 2005 Youth Risk Behavior Survey (United States Department of Health and Human Services and Centers for Disease Control and Prevention): "In an average week when you are in school, how many days do you participate in physical education/gym-like activities?" 36 Answer options were ordinal, and included 0 through 5 days. We also adapted an item from the Centers for Disease Control and Prevention's National Health and Nutrition Examination Survey (NHANES) Physical Activity and Physical Fitness Questionnaire (PAQ-SP): "Over the past 30 days, how often have you participated in any physical activity designed to strengthen your muscles (lifting weights, push-ups, sit-ups, pull-ups)?"37 Answer options included three checkboxes: "None," "daily," and "weekly." With regard to readiness we used standard readiness rulers recommended by the American Medical Association" ${ }^{21}$; "On a scale from 1 to 10 , with 10 being completely ready to take action, how ready are you to lose weight?" and "On a scale from 1 to 10, with 10 being completely confident, how confident are you in your ability to achieve a healthy weight?"

\section{Data Analysis}

Program status was recorded as binary (dropout at any time after joining the program vs. completion of the 6month program). Program completion was defined as attendance at the required introductory and final comprehensive appointments. Program completers were compared to noncompleters on the basis of demographic information collected from the enrollment questionnaire (age, gender, family income, Medicaid status, race, parent 
educational level), responses to the two exercise-related questions, and readiness scales using chi-square tests and Fisher exact tests when there was unsatisfactory group membership. Reponses to readiness rulers were initially treated as continuous, and participants were subsequently divided into tertiles $(0-5=$ not high, $6-8=$ high, $9-10=$ very high). Univariate and multivariate binary logistic regression analyses using program completion as the dependent variable and the aforementioned significant variables as predictors were performed to generate odds ratios (ORs). Demographic variables that significantly differed between groups were included as covariates in the regression model to check for a significant effect on the relationship between pretreatment exercise and/or readiness on program completion. All statistical analyses were performed with STATA version 12 by STATAcorp LP (College Station, TX). Statistical significance was set a priori as $p<0.05$. This study was approved by the Institutional Review Board of the University of Michigan Medical School and written parental consent/child assent for MPOWER participation was previously obtained.

\section{Results}

A total of 146 patients joined the MPOWER program during the study period (Table 1). Among those who joined,

\section{Table I. Descriptive Statistics of Completers versus Noncompleters}

\begin{tabular}{|c|c|c|c|}
\hline & Completers $(n=78)$ & Noncompleters $(n=68)$ & $p$ value \\
\hline Age (years, mean $\pm S D$ ) & $14.4 \pm 1.7$ & $14.2 \pm 1.8$ & NS \\
\hline BMI $\left(\mathrm{kg} / \mathrm{m}^{2}\right.$, mean $\left.\pm \mathrm{SD}\right)$ & $43.9 \pm 11.3$ & $43.0 \pm 10.5$ & NS \\
\hline \multicolumn{3}{|l|}{ Gender } & NS \\
\hline Female & $69 \%$ & $66 \%$ & \\
\hline Insurance & & & $<0.001$ \\
\hline Medicaid & $31 \%$ & $63 \%$ & \\
\hline \multicolumn{3}{|l|}{ Race } & NS \\
\hline White & $60 \%$ & $43 \%$ & \\
\hline Black & $35 \%$ & $46 \%$ & \\
\hline Other & $5 \%$ & $12 \%$ & \\
\hline \multicolumn{3}{|l|}{ Mother, educational level } & NS \\
\hline Some high-school to high-school/GED & $14 \%$ & $25 \%$ & \\
\hline Some college to Associate degree & $45 \%$ & $50 \%$ & \\
\hline Bachelor's degree to Master's degree & $29 \%$ & $12 \%$ & \\
\hline Professional to Doctoral & $6 \%$ & $6 \%$ & \\
\hline Unknown & $5 \%$ & $7 \%$ & \\
\hline \multicolumn{3}{|l|}{ Father, educational level } & NS \\
\hline Some high-school to high-school/GED & $41 \%$ & $50 \%$ & \\
\hline Some college to Associate degree & $18 \%$ & $22 \%$ & \\
\hline Bachelor's degree to Master's degree & $22 \%$ & $7 \%$ & \\
\hline Professional to Doctoral & $9 \%$ & $4 \%$ & \\
\hline Unknown & $10 \%$ & $16 \%$ & \\
\hline \multicolumn{3}{|l|}{ Household Income } & 0.001 \\
\hline Less than $\$ 25,000$ & $35 \%$ & $59 \%$ & \\
\hline$\$ 25,000-\$ 49,999$ & $21 \%$ & $23 \%$ & \\
\hline$\$ 50,000-\$ 74,999$ & $11 \%$ & $11 \%$ & \\
\hline Greater than or equal to $\$ 75,000$ & $33 \%$ & $6 \%$ & \\
\hline
\end{tabular}

Note: Percentages may not sum to $100 \%$ because of rounding.

$\mathrm{SD}$, standard deviation; NS, not significant. 
78 completed the 6-month program (53\%). Among those who did not complete the program, $47 \%$ and $53 \%$ discontinued the program during months $0-3$ and 3-6, respectively.

\section{Group Comparisons}

Demographics. MPOWER completers' mean initial age $(14.4 \pm 1.7$ years $)$ and BMI $\left(43.9 \pm 11.3 \mathrm{~kg} / \mathrm{m}^{2} ; 99^{\text {th }}\right.$ percentile) did not differ from noncompleters (14.2 \pm 1.8 years; BMI $43.0 \pm 10.5 \mathrm{~kg} / \mathrm{m}^{2} ; 99^{\text {th }}$ percentile) (Table 1). More noncompleters were economically disadvantaged per selfreported household income of less than $\$ 25,000\left(\chi^{2}=16.8\right.$; $p=0.001)$ and were Medicaid enrollees $\left(\chi^{2}=15.4\right.$; $p<0.001$; Table 1). There were no other significant differences between the completers and non-completers in terms of gender, race, and parent education level.

Standard readiness rulers. When asked "...how ready are you to lose weight?", $6 \%, 22 \%$, and $72 \%$ of respondents rated their readiness as not high, high, and very high, respectively. When asked "... how confident are you in your ability to achieve a healthy weight?", $16 \%, 36 \%$, and $48 \%$ rated their confidence as not high, high, and very high respectively. There was no relationship between either the "...how ready are you to lose weight?" item (Fisher $p=0.595$ ) or the "how confident are you in your ability to achieve a healthy weight?" item (Fisher $p=0.455$ ) and program completion.

Pretreatment exercise. There was no difference between self-reported pretreatment physical education/gym-like activities between completers and noncompleters (Table 2). However, a significant between groups difference emerged when comparing none, daily, and weekly SA in the 30 days prior to program enrollment $\left(\chi^{2}=14.3 ; p=0.001\right)$. There was no relationship between readiness level from either readiness item and either exercise item ("...how ready are you" vs. SA Fisher $p=0.129$; vs. physical education Fisher $p=0.697$; “...how confident are you" vs. SA Fisher $p=0.402$; vs. physical education Fisher $p=0.626$ ).

Logistic regressions. Binary logistic regression was performed with program completion used as the outcome variable and the significant demographic and SA frequencies used as the predictors. On the basis of this model, Medicaid insurance was associated with significantly lower odds of program completion [reference: no Medicaid, OR 0.26, 95\% confidence interval (CI) $0.13-0.51 ; p<0.001]$. Likewise, compared to individuals whose household income was less than $\$ 25,000$, those with household incomes greater than or equal to $\$ 75,000$ were over nine times more likely to complete the program (95\% CI 2.84-29.36; $p<0.001)$. No significant differences were found between other levels of income compared to less than $\$ 25,000$ annually.

Furthermore, compared to participants who self-reported no SA in the 30 days prior to answering the questionnaire, individuals who self-reported weekly SA were 3.18 times more likely to complete the program (95\% CI $1.51-6.68 ; p=0.002)$. Self-reported daily SA during the

\begin{tabular}{|c|c|c|c|}
\hline & $\begin{array}{c}\text { Completers } \\
(n=78)\end{array}$ & $\begin{array}{c}\text { Noncompleters } \\
(n=68) \\
\%\end{array}$ & $P$ value \\
\hline \multicolumn{3}{|c|}{ Physical education/gym-like activities } & NS \\
\hline $\begin{array}{l}0 \text { days per week } \\
\text { on average }\end{array}$ & 53 & 43 & \\
\hline $\begin{array}{l}\text { I day per week } \\
\text { on average }\end{array}$ & 8 & 6 & \\
\hline $\begin{array}{l}2 \text { days per week } \\
\text { on average }\end{array}$ & 6 & 3 & \\
\hline $\begin{array}{l}3 \text { days per week } \\
\text { on average }\end{array}$ & 5 & 10 & \\
\hline $\begin{array}{l}4 \text { days per week } \\
\text { on average }\end{array}$ & 5 & 4 & \\
\hline $\begin{array}{l}5 \text { days per week } \\
\text { on average }\end{array}$ & 23 & 33 & \\
\hline \multicolumn{3}{|c|}{ Strengthening activity in the past 30 days } & 0.001 \\
\hline None, on average & 29 & 47 & \\
\hline Daily, on average & 9 & 22 & \\
\hline $\begin{array}{l}\text { Weekly, on } \\
\text { average }\end{array}$ & 62 & 31 & \\
\hline
\end{tabular}

Note: Percentages may not sum to $100 \%$ because of rounding. NS, not significant.

30 days prior to completion of the questionnaire was not associated with program completion, and, compared to those who performed daily SAs, weekly SA exercisers were 4.90 times more likely to complete the program $(95 \%$ CI 1.74-13.77; $p=0.003$; Table 3). Further analyses revealed that SA, at any frequency, was more likely to be performed by adolescents from households in which the annual income was greater than or equal to $\$ 75,000$ (95\% CI vs. households who earn less than \$25,000: 1.1-9.72; $p=0.032)$. Other levels of income (e.g., incomes between $\$ 25,000$ and $\$ 75,000$ ) did not differ from the less than $\$ 25,000$ group. Adolescents enrolled in Medicaid were less likely to perform any amount of SA (95\% CI 0.256-0.998; $p=0.05)$. Because insurance status and income were both found to be independently significantly associated with program completion and level of SA performed, they were included in the multivariate logistic regression. Neither income nor insurance status had a significant impact on the main effect of weekly SA on program completion, reflected in the statistically significant adjusted odds ratios for weekly SA (reference: no SA, OR 2.43, 95\% CI 1.065.58, $p=0.036$; reference: daily SA, OR 4.69, 95\% CI 1.45-15.14, $p=0.010$; Table 3). No other demographic variables were associated with $\mathrm{SA}$ and program completion. 
Table 3. Models of Independent Predictors of Program Completion

\begin{tabular}{|l|c|c|c|} 
Predictor & $\begin{array}{c}\text { Unadjusted odds ratio } \\
\text { (95\% confidence interval) }\end{array}$ & $\begin{array}{c}\text { Adjusted odds ratio } \\
\text { (95\% confidence interval) }\end{array}$ & $\begin{array}{c}\text { Prob }>\chi^{2} \\
\text { (unadjusted/adjusted) }\end{array}$ \\
\hline Pretreatment weekly SA (vs. none) & $3.18(1.51-6.68)$ & $2.43(1.06-5.58)$ & $0.002 / 0.036$ \\
\hline Pretreatment weekly SA (vs. daily) & $4.9(1.74-13.77)$ & $4.69(1.45-15.14)$ & $0.003 / 0.01$ \\
\hline
\end{tabular}

\section{Discussion}

In the current study, $53 \%$ of adolescents completed the 6-month intensive weight management intervention. This is consistent with previously reported attrition rates, which generally hover around 50\% (range 33-73\%) in programs lasting at least 6 months. ${ }^{11-16,34,38-40}$ Like previous studies, lower socioeconomic status and Medicaid insurance were strong predictors of program dropout. Unlike prior studies, we did not find race to be a significant predictor of program attrition.

This preliminary study is the first to find that pretreatment weekly SA was strongly associated with program completion, compared to those who performed SA never or daily. Additionally, our pretreatment readiness scales were unable to differentiate program completers from noncompleters and did not relate to pretreatment weekly exercise item responses. These data may have implications for clinical practice and elucidate pathways for future research.

This analysis failed to find an association between selfreported readiness and program completion, and adds to the literature citing the inconsistent utility of these widely used scales in adults, ${ }^{27,28,41,42}$ and adolescents. ${ }^{25}$ The psychological construct of readiness is likely a complex interplay between motivation, commitment, self-awareness, satisfaction, esteem, and self-efficacy, and thus the ability of a simple 1-10 scale to measure true readiness may be limited in many instances. ${ }^{43-45}$ Additionally, even though one may be "ready" to lose weight, the aforementioned logistical, family, and demographic factors may preclude program completion. Last, in our study population, parental readiness may be at least as important as our patients' readiness, and this has been shown in prior studies. ${ }^{46}$

In an effort to use past behaviors as a more robust surrogate of readiness and thus of program completion, we analyzed self-reported pretreatment SA. In general, routine pretreatment SA may improve feelings of self-worth prior to program onset ${ }^{47}$ and may reflect commitment to work to achieve weight loss. ${ }^{14}$ In our analysis, we found that pretreatment weekly SA, compared to activities performed never or daily, predicted program completion. The reasons behind this finding are unclear.

Specifically, it is not known why patients who practiced SA daily were much less likely to complete the weight management program compared to those who performed SA on a weekly basis. It is possible that teens who practice weekly SA may be more comfortable with the notion of weekly progress, which is one of the core tenets of our program. Unlike those who perform SA daily, these individuals may be especially receptive to our message that successful weight loss is more analogous to a marathon than a sprint. Furthermore, in a recent qualitative study exploring the perspectives of MPOWER patients and their parents, we found that our weekly SA sessions were one of the most enjoyable components of the program. ${ }^{48}$ Thus, patients who perform pretreatment weekly SA may be especially likely to enjoy both the mission and structure of the program, and this has been linked to program completion in prior studies. ${ }^{11,16}$

Furthermore, individuals who perform SA daily may eventually find their routine and weight loss goals too challenging and unrealistic. This occurrence has been theorized to contribute to burnout ${ }^{49}$ and weight management program attrition, ${ }^{50,51}$ but this has not been formally studied in the pediatric population. Also, individuals who attempt to accomplish tasks that are too repetitive may eventually become bored with their routine. ${ }^{52}$ Thus, although those who perform daily pretreatment SA may have commendable commitment at the outset, burnout and boredom may eventually lead to waning motivation that compromises program completion. Therefore, a "slow and steady" approach may be more beneficial.

With regard to participation in school-based gym-like activities, there was no relationship between frequency of this exercise and program completion. Although the reasons for this are unclear, this may reflect the fact that school-based exercise is largely out of the adolescents' control. Thus, it is likely a poor surrogate for the other psychological factors that may be important in program completion.

The content of this preliminary study should be considered in the context of its limitations. First, both of the measures used for obtaining pretreatment physical activity, although used in national surveillance surveys and prior studies, ${ }^{53,54}$ are inherently limited. The gym-like activity item limits respondents to reporting only in-school activity and not in- and out-of-school activity. Also, responses may depend on the specific school, grade, state regulations, and time of year. Post hoc analyses did not show any difference in response by season of enrollment but did show that older patients were more likely to perform no gym-like activity, which may reflect the decreasing opportunities for curricular gym-like activities upon entering high school.

Additionally, the strengthening-activities item was not ideal because of the unequal intervals between none, daily, 
and weekly; it is unclear how a participant differentiates between daily and weekly. It also asks teens to recall SA over the past 30 days, which may be demanding for this age group. Last, this item may also be subject to seasonal and age-based variation. However, post hoc analyses revealed no difference in age and seasonality between respondents.

Furthermore, with only two items addressing physical activity, it is difficult to confidently draw specific conclusions with regard to the nature of the exercise performed. The examples of SAs listed for our participants to consider probably measured both resistance training and calisthenics. The specific effects of these different types of exercises should be analyzed in future studies to better understand the factors that contribute to program completion. Future prospective studies would benefit from the use of validated complete physical activity questionnaires such as the Physical Activity Questionnaire for Children (PAQ-C), physical activity logs, or accelerometers.

\section{Conclusion}

This study provides preliminary evidence suggesting that adolescents who report pretreatment weekly SA are significantly more likely to complete a 6-month weight management program than those who do not. Additionally, standard readiness scales may fail to be useful in predicting program completion. This finding should be confirmed in future studies, given both the frequency with which these scales are used in practice and the scarcity of formal investigation $^{25}$ in the pediatric population.

The use of pretreatment behaviors more generally, and pretreatment SA, may be helpful in screening tools to assist in the determination of those patients who are most likely to remain engaged in a weight management program, which may in turn enhance resource use decisions. Further investigation is needed to clarify the mechanism through which pretreatment weekly SA impacts program completion and its possible relationship to the motivations and outcome expectations necessary to complete a long-term weight loss program. In addition, potential associations between pre-treatment SA and other outcomes of weight management interventions (such as change in BMI, anthropomorphic measurements, and metabolic risk factors) should be elucidated.

\section{Author Disclosure Statement}

No competing financial interests exist.

\section{References}

1. Ogden CL, Carroll MD, Flegal KM. High body mass index for age among US children and adolescents, 2003-2006. JAMA 2008; 299:2401-2405.

2. Ogden CL, Carroll MD, Kit BK, et al. Prevalence of obesity and trends in body mass index among US children and adolescents, 1999-2010. JAMA 2012;307:483-490.
3. Troiano RP, Flegal KM. Overweight children and adolescents: Description, epidemiology, and demographics. Pediatrics 1998; 101:497-504.

4. Dietz WH. Health consequences of obesity in youth: Childhood predictors of adult disease. Pediatrics 1998;101:518-525.

5. Woolford SJ, Gebremariam A, Clark SJ, et al. Incremental hospital charges associated with obesity as a secondary diagnosis in children. Obesity (Silver Spring) 2007;15:1895-1901.

6. Hampl SE, Carroll CA, Simon SD, et al. Resource utilization and expenditures for overweight and obese children. Arch Pediatr Adolesc Med 2007;161:11-14.

7. John J. Economic perspectives on pediatric obesity: Impact on health care expenditures and cost-effectiveness of preventive interventions. Nestle Nutr Workshop Ser Paediatr Program 2010; 66:111-124.

8. Stice E, Shaw H, Marti CN. A meta-analytic review of obesity prevention programs for children and adolescents: The skinny on interventions that work. Psychol Bull 2006;132:667-691.

9. Skelton JA, Goff DC Jr, Ip E, et al. Attrition in a multidisciplinary pediatric weight management clinic. Child Obes 2011;7:185-193.

10. Skelton JA, Beech BM. Attrition in paediatric weight management: A review of the literature and new directions. Obes Rev 2011;12:e273-e281.

11. Cote MP, Byczkowski T, Kotagal U, et al. Service quality and attrition: An examination of a pediatric obesity program. Int J Qual Health Care 2004;16:165-173.

12. Heinberg LJ, Kutchman EM, Berger NA, et al. Parent involvement is associated with early success in obesity treatment. Clin Pediatr (Phila) 2010;49:457-465.

13. Tershakovec AM, Watson MH, Wenner WJ Jr, et al. Insurance reimbursement for the treatment of obesity in children. $\mathrm{J}$ Pediatr 1999; $134: 573-578$

14. Zeller M, Kirk S, Claytor R, et al. Predictors of attrition from a pediatric weight management program. J Pediatr 2004;144:466-470.

15. Barlow SE, Ohlemeyer CL. Parent reasons for nonreturn to a pediatric weight management program. Clin Pediatr (Phila) 2006;45: 355-360.

16. Kitscha CE, Brunet K, Farmer A, et al. Reasons for non-return to a pediatric weight management program. $\underline{\text { Can J Diet Pract Res }}$ 2009;70:89-94.

17. Barlow SE, Dietz WH. Obesity evaluation and treatment: Expert Committee recommendations. The Maternal and Child Health Bureau, Health Resources and Services Administration and the Department of Health and Human Services. Pediatrics 1998; 102:E29.

18. Spear BA, Barlow SE, Ervin C, et al. Recommendations for treatment of child and adolescent overweight and obesity. Pediatrics 2007;120(Suppl 4):S254-S288.

19. Jonides L, Buschbacher V, Barlow SE. Management of child and adolescent obesity: Psychological, emotional, and behavioral assessment. Pediatrics 2002;110:215-221.

20. Krebs NF, Himes JH, Jacobson D, et al. Assessment of child and adolescent overweight and obesity. Pediatrics 2007;120(Suppl 4):S193-S228.

21. Kushner RF. Assessing Readiness and Making Treatment Decisions. Roadmaps for Clinical Practice: Case Studies in Disease Prevention and Health Promotion-Assessment and Management of Adult Obesity: A Primer for Physicians. American Medical Association: Chicago, Illinois, 2003, pp. 4-5.

22. Rollnick S, Pip M, Butler C. Health Behavior Change: A Guide for Practitioners. Elsevier Health Sciences: Philadephia, Pennsylvania, 1999. 
23. Berg-Smith SM, Stevens VJ, Brown KM, et al. A brief motivational intervention to improve dietary adherence in adolescents. The Dietary Intervention Study in Children (DISC) Research Group. Health Educ Res 1999;14:399-410.

24. Glascoe FP, Oberklaid F, Dworkin PH, et al. Brief approaches to educating patients and parents in primary care. Pediatrics 1998; 101:E10.

25. Resnicow K, Taylor R, Baskin M, et al. Results of go girls: A weight control program for overweight African-American adolescent females. Obes Res 2005;13:1739-1748.

26. Teixeira PJ, Going SB, Houtkooper LB, et al. Pretreatment predictors of attrition and successful weight management in women. Int J Obes Relat Metab Disord 2004;28:1124-1133.

27. Teixeira PJ, Going SB, Houtkooper LB, et al. Weight loss readiness in middle-aged women: Psychosocial predictors of success for behavioral weight reduction. J Behav Med 2002;25:499-523.

28. West DS, Harvey-Berino J, Krukowski RA, et al. Pretreatment weight change is associated with obesity treatment outcomes. Obesity (Silver Spring) 2011;19:1791-1795.

29. Teixeira PJ, Palmeira AL, Branco TL, et al. Who will lose weight? A reexamination of predictors of weight loss in women. Int $J$ Behav Nutr Phys Act 2004;1:12.

30. Lowe MR, Foster GD, Kerzhnerman I, et al. Restrictive dieting vs. "undieting" effects on eating regulation in obese clinic attenders. Addict Behav 2001;26:253-266.

31. Clark MM, Niaura R, King TK, et al. Depression, smoking, activity level, and health status: Pretreatment predictors of attrition in obesity treatment. Addict Behav 1996;21:509-513.

32. Barnstuble JA, Klesges RC, Terbizan D. Predictors of weight loss in a behavioral treatment program. Behav Ther 1986;17:288294.

33. Ryan RM, Deci EL. Self-determination theory and the facilitation of intrinsic motivation, social development, and well-being. $\underline{\mathrm{Am}}$ Psychol 2000;55:68-78.

34. Sothern MS, Schumacher H, von Almen TK, et al. Committed to kids: An integrated, 4-level team approach to weight management in adolescents. J Am Diet Assoc 2002;102:S81-S85.

35. Brownell KD. Diet, exercise and behavioural intervention: The nonpharmacological approach. Eur J Clin Invest 1998;28(Suppl 2):19-21; discussion 22.

36. Eaton DK, Kann L, Kinchen $\mathrm{S}$, et al. Youth risk behavior surveillance-United States, 2005. MMWR Surveill Summ 2006; 55:1-108.

37. Centers for Disease Control and Prevention. Physical Activity Data Documentation, Codebook, and Frequencies. 2005-2006. Available at www.cdc.gov/nchs/nhanes/nhanes2005-2006/PAQ_D.htm/. Last accessed April 10, 2013.

38. Skelton JA, DeMattia LG, Flores G. A pediatric weight management program for high-risk populations: A preliminary analysis. Obesity (Silver Spring) 2008;16:1698-1701.

39. Kirk S, Zeller M, Claytor R, et al. The relationship of health outcomes to improvement in BMI in children and adolescents. Obes Res 2005;13:876-882.

40. Denzer C, Reithofer E, Wabitsch M, et al. The outcome of childhood obesity management depends highly upon patient compliance. Eur J Pediatr 2004;163:99-104.
41. Fontaine KR, Cheskin LJ, Allison DB. Predicting treatment attendance and weight loss: Assessing the psychometric properties and predictive validity of the Dieting Readiness Test. J Pers Assess 1997;68:173-183.

42. Jeffery RW, French SA, Rothman AJ. Stage of change as a predictor of success in weight control in adult women. Health Psychol 1999; 18:543-546.

43. Teixeira PJ, Going SB, Sardinha LB, et al. A review of psychosocial pre-treatment predictors of weight control. Obes Rev 2005;6:43-65.

44. Moroshko I, Brennan L, O'Brien P. Predictors of dropout in weight loss interventions: A systematic review of the literature. Obes Rev 2011;12:912-934.

45. Fabricatore AN, Wadden TA, Moore RH, et al. Predictors of attrition and weight loss success: Results from a randomized controlled trial. Behav Res Ther 2009;47:685-691.

46. Rhee KE, De Lago CW, Arscott-Mills T, et al. Factors associated with parental readiness to make changes for overweight children. Pediatrics 2005;116:e94-e101.

47. Velez A, Golem DL, Arent SM. The impact of a 12-week resistance training program on strength, body composition, and selfconcept of Hispanic adolescents. J Strength Cond Res 2010;24: $1065-1073$

48. Woolford SJ, Sallinen BJ, Schaffer S, et al. Eat, play, love: Adolescent and parent perceptions of the components of a multidisciplinary weight management program. Clin Pediatr (Phila) 2012; 51:678-684.

49. Mannix ET, Steinberg HO, Faryna S, et al. The role of physical activity, exercise, and nutrition in the treatment of obesity. In: Goldstein DJ, ed. The Management of Eating Disorders and Obesity. Humana Press: Totowa, New Jersey, 2005, p. 195.

50. Dalle Grave R, Calugi S, Molinari E, et al. Weight loss expectations in obese patients and treatment attrition: An observational multicenter study. Obes Res 2005;13:1961-1969.

51. Fabricatore AN, Wadden TA, Womble LG, et al. The role of patients' expectations and goals in the behavioral and pharmacological treatment of obesity. Int J Obes 2007;31:1739-1745.

52. Csikszentmihalyi M. Flow: The Psychology of Optimal Experience. HarperCollins: New York, New York, 1991.

53. Cheng YJ, Gregg EW, De Rekeneire N, et al. Muscle-strengthening activity and its association with insulin sensitivity. Diabetes Care 2007;30:2264-2270.

54. Centers for Disease Control and Prevention. Physical activity levels of high school students-United States, 2010. MMWR Morb Mortal Wkly Rep 2011;60:773-777.

Address correspondence to:

Susan J. Woolford, MD, MPH

Medical Director

C.S. Mott Children's Hospital Pediatric Comprehensive Weight Management Center 300 North Ingalls Building, Room 6D20 Ann Arbor, MI 48109-5456

E-mail: Swoolfor@med.umich.edu 
This article has been cited by:

1. Chirita-Emandi Adela, Puiu Maria. 2014. Outcomes of Neurofeedback Training in Childhood Obesity Management: A Pilot Study. The Journal of Alternative and Complementary Medicine 20:11, 831-837. [Abstract] [Full Text HTML] [Full Text PDF] [Full Text PDF with Links] 